\section{Major Investments, with Changes to Come}

\begin{abstract}
F.D. Santos from the Centro de Fisica Nuclear da Universidade de Lisboa, in a brief survey of physics in Portugal, highlights the main features of physics research and education.
\end{abstract}

There are very few publications dealing with the recent evolution and present situation of physics research and higher education in Portugal. The most complete analysis was published in 1990 in Gazeta de Física, the Portuguese Physical Society's bulletin [1]. It addressed the situation in eight major subfields of physics (highenergy, nuclear, atomic and molecular, plasma, and condensed matter physics, optics) and related areas (astronomy and astrophysics and geophysics, including atmospheric sciences, physical oceanography and seismology). In summarising the current status of physics in Portugal I shall use the same broad classification, giving particular attention to the subfields of physics.

Information on the number of physicists, projects and funding in the different subfields is not at present directly available from governmental or non-governmental agencies. It is therefore extremely difficult to give reliable answers to questions such as: how many $\mathrm{PhD}$-level physicists and $\mathrm{PhD}$ and $\mathrm{MSc}$ students are doing research in condensed matter physics, for instance? What are the main research areas, the funding levels, the number and types of publications, the contracts with industry, etc. for say the last five years?

The funding mechanisms in Portugal for science in general and for physics in particular are quite complex and have recently undergone substantial changes. In particular, 1992 saw the untimely extinction of the Instituto Nacional de Investigaçäo Cientifica (INIC) - the agency that provided the basic funding for research in universities. Its functions were taken over

Filipe Santos is a professor of physics with the Centro de Fisica Nuclear da Universidade de Lisboa, Av. Prof. Gama Pinto, 2, P-1699 Lisbon Codex, having joined the university in 1972 after working as a research fellow with Portugal's Nuclear Energy Authority in Sacavém. Professor Santos studied in Lisbon and Porto and received his PhD in nuclear physics from the University of London in 1968. He presently chairs the CERN-Portugal Scientific Committee, having served as Dean of Lisbon University's Faculty of Sciences in 1985-91 and as the General Secretary of the Portuguese Physical Society in 1984-90). by the Junta Nacional de Investigaçäo Cientifica e Tecnológica (JNICT) which launched in 1994 a two-year programme to reorganize and support research, in particular the research centres previously funded by INIC. The programme's budget for physics in 1994 and 1995 was about 1.2 million ECU p.a. (at today's exchange rate) distributed to 24 centres and involving some $260 \mathrm{PhDs}$, if one includes astronomy and geophysics.

It is too early to assess the impact of the organizational changes. Nevertheless, it is useful to discuss the important characteristics of physics in Portugal.

\section{International Research}

Additional funding for research groups in the JNICT centres is obtained on a very competitive basis from international programmes as well as from nonJNICT national sources. The amount is extremely variable, although on average probably on the order of $50-100 \%$ of the total research budget for the active groups.

This number does not apply to highenergy physics (HEP) which has benefited from a specific support programme since 1986. The agreement between Portugal and CERN established that during a 10year period a decreasing fraction of the CERN membership fee would be invested in developing high-energy physics in the country. Initially, the percentage for local funding was reduced at an annual rate of $10 \%$, but a renegotiated agreement

\section{Lisbon's O Monasteiro dos Jerónimos e a Praça do} Império. Portugal, with some $240 \mathrm{PhD}$-level physicsts and a population of 9-10 million, joined the European Community in 1986.

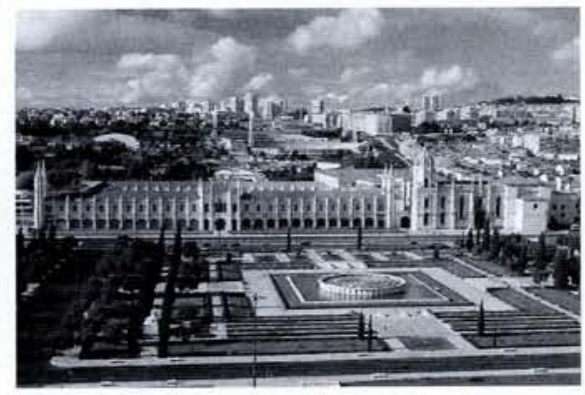

F.D. Santos

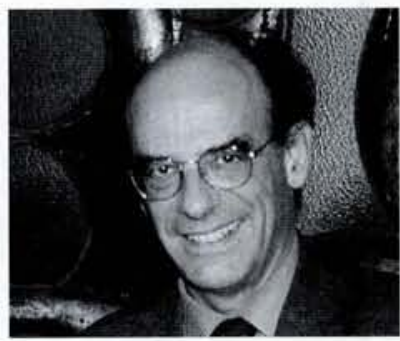

extended it to 1996 with a residual fraction of $5 \%$. Under this agreement, research projects in Portugal amounted to a total of 12.7 million ECU in 1990-95, with $68 \%$ for HEP, $20 \%$ for other areas of physics and $12 \%$ for other areas of science and technology. During the six-year period the total CERN subscription totalled 23.4 million ECU and in 1996 the subscription is 8.4 million ECU. These numbers are quite large compared with the JNICT budget of nearly 10.7 million ECU for physics research (the European Union's CîENCIA - see below; research projects and current expenses of physics research centres) in all of physics, excluding HEP, for 1990-95.

The Portugal-CERN agreement has been very successful in developing highenergy physics. The number of HEP PhDs increased from 23 in 1986 to about 60 in 1996 which is close to one-quarter of the total number of physics PhDs in the country. HEP research is of high quality and the community is deeply involved in the current CERN projects, including the LHC. It is an excellent example of a sizable and well-planned investment in a specific research area that has produced good results and a dynamic community.

Astronomy is also an area that has received special attention and investment in recent years. A 10-year cooperation agreement between Portugal and the European Southern Observatory (ESO) was signed in 1990 to prepare for full membership, so an ESO subscription is not paid at present. The total funding of research projects in astronomy and astrophysics during 1991-95 was about 1.4 million ECU - an investment that has been very successful in developing astronomy. The number of observing astronomers from Portugal holding a $\mathrm{PhD}$ has increased substantially in the last six years and although still small, now exceeds 10. Observations at the La Silla ESO Observatory, Cerro Tololo Inter-American Observatory (both in Chile) and the VLA (New Mexico, USA) are now relatively frequent (Lisbon University's astronomy and astrophysics group obtained nine observing 
periods at the three observatories during 1994 and 1995).

Portugal manifested some years ago an interest in becoming a member of the European Space Agency (ESA). Negotiations have been long and associate membership, now planned for 1996, will be very important for the development of not only astronomy but also various fields of physics. It is expected that, contrary to what happened in other European countries [2], the payment of the membership fees for CERN and ESA will not cause budget problems, particularly for physics.

In recent years there has been a perceptible movement of academic physicists to more applied physics, particularly towards materials science, lasers and optics, physics of detectors, superconductors and biophysics. This trend has attracted a sizable amount of funding from European Union (EU) programmes and promoted strong international networks.

\section{Physics Research}

The vast majority of physicists are academics and hold positions in universities. However, present funding of the public universities contemplates teaching and related activities, and only an extremely low level of support for research activities. University budgets are based on the number of students and the type of course they follow, and not on an assessment of the level and quality of research carried out by faculty members. A new Ministry of Science and Technology is presently responsible for research funding.

Physics research is carried out by the academics in research centres which have a very loose administrative structure and are, in practice, to a large extent independent from the universities. Some of these centres are private in the sense that they are outside the government's administration. For instance, a few are associated with private foundations. An interesting example is the Laboratory for Particle Physics and Instrumentation (Laboratorio de Instrumentação e Particulas - LIP). It is a private institution devoted primarily to high-energy experimental physics that has successfully guided and supported the activity of most of Portugal's experimental particle physicists since the country joined CERN in 1986. LIP has two branches, the main one being in Lisbon and the other at Coimbra University's Physics Department.

Research in physics is also performed in some state laboratories [3], often in close collaboration with academic physicists. The main emphasis is on applied

\section{Physics in Portugal}

Physics research in Portugal is mainly carried out in Oporto, Coimbra and Lisbon. There are also physics research groups, although still relatively small but very active, at the University of Aveiro, the University of Beira Interior (Covilha), the University of Evora and the University of Algarve (Faro) [4].

Oporto ( $\approx 50$ Ph.D-level physicists)

Most active research centres: condensed matter physics; materials science and technology; astrophysics.

University of Oporto

- Physics Centre: long tradition in condensed matter physics; main research fields are transport phenomena, superconductivity, specific heat and magnetic properties, opto-electronics and paleomagnetism.

- Astronomy Centre and Astronomical Observatory: space geodesy and applications.

- CÎENCIA Institute: recently inaugurated; specializes in materials science and technology.

- Centre for Astrophysics: mainly research projects in stellar astrophysics, hydrodynamic fluids in the interstellar medium, stellar winds and theoretical cosmology.

Coimbra ( $\approx 40$ PhD-level physicists)

Main areas: nuclear and radiation physics; experimental particle physics; materials science; instrumentation; optics.

University of Coimbra

- Department of Physics: well known in several areas of physics research. One is theoretical nuclear physics at the Theoretical Physics Centre (nuclear collective models, chiral models and more generally many-body theories).

- Laboratory for Instrumentation and Particle Physics (LIP): specializes in detector systems for high-energy physics.

Lisbon $(\approx 150$ PhD-level physicists)

Universities

Instituto Superior Técnico

- Centre for Physics of the Fundamental Interactions and the Multidisplinary Centre for Astrophysics: Portugal's strongest research centres for theoretical particle physics. Main research areas: tests of the standard model, weak and strong interactions, CP violation, quantum gravity, cosmology and nuclear physics.

- Nuclear Fusion Centre: diagnostic techniques, transport properties in fusion plasmas using microwave reflectometry, tokamak, plasma oscillations and fluctuations and current drive. Main facility: 7 kA current ISTTOK tokamak.

- Electrodynamics Research Centre: optics, plasma physics; gas discharges.

- Molecular Physics Centre

- Groups active in earth and environmental physics, optics and solid-state physics.

\section{University of Lisbon}

Main research groups: condensed matter; biophysics (a new Institute of Biophysics and Biomedical Engineering). - Groups active in applications of nuclear methods to materials science and technology; use the ITN's Van der Graaff accelerator and ion implanter (see below).

- Atomic Physics Centre

- Nuclear Physics Centre: strong groups in theoretical nuclear physics; theoretical cosmology; astronomy and astrophysics (active observational group; main areas of research: star formation; galactic structure and dynamics; BL Lac objects).

- Centre for Geophysics and the Infante D. Luis Institute of Geophysics: meteorology; climatology; seismology; marine and applied geophysics.

- Institute of Oceanography: newly built; physical oceanography.

New University of Lisbon

Main areas: solid-state and molecular physics, notably polymers, liquid crystals, surface analysis, molecular interactions and photon-electron spectroscopy.

Laboratory for Particle Physics and Instrumentation (LIP): base for Portuguese experimental particle physics research. Current projects: collaboration in the NA50 and DELPHI experiments at CERN; participation in the ATLAS and CMS detectors for LHC; data acquisition, processing and transmission technologies for high-energy physics.

\section{State laboratories}

- Institute for Nuclear Technology (ITN): located at Sacavém on the outskirts of Lisbon. Main facilities:

-1 MW research nuclear reactor of the swimming-pool type (operational since 1961);

- 3.1 MeV Van de Graaff accelerator

- high-current ion implanter (recently installed)

- Instituto Nacional de Engenharia e Tecnologia Industrial (INETI): activities in various fields related to physics, particularly condensed matter and optics.

physics and some have relatively large experimental facilities (see insert).

\section{European Union Impact}

Since $1989 / 90$ a large regional development programme in science and technology called CIENCIA, funded in part by the EU, has supported the construction of experimental facilities in materials science, energy and production technologies and the exact sciences. Some of the projects that were funded have physicists as principal investigators and carry out research in various fields of physics, espe- 
cially those related to materials science. The total investment in CÎENCA facilities that have physicists as principal investigators is of the order of 5.2 million ECU..

Although it is probably too early to evaluate CÎENCIA's impact on the level and quality of the country's research, it is widely appreciated that the new infrastructure is very important for promoting the excellence and international competitiveness of experimental physics and for creating research links with industry. Information on the present operational situation of the CÎENCIA facilities, their national and international networking, accessibility to external users, scientific results and contracts is not yet available.

CîNCIA was followed up in 1994 with a large, six-year EU-funded regional development programme in science and technology called PRAXIS XXI, which was launched with a total budget of 574 million ECU and geared more towards training and the funding of research projects than to the construction of facilities.

\section{University Courses}

The number of university students in Portugal has increased dramatically by a factor of nearly four since the beginning of the $1980 \mathrm{os}$. This growth resulted in part from the creation of a relatively large number of private universities, which now have more than $35 \%$ of the total number of some 300 ooo university students. Tuition fees are on average of the order of 1800 ECU p.a. whereas public universities are at present free. Very few private universities offer science and technology courses, and none awards a degree in physics (10 public universities out of a total of 14 are currently offering physics degrees).

The size of physics departments varies greatly: two have more than 60 faculty members (University of Lisbon and the Technical University of Lisbon) and five less than 16. In the academic year 1992/93, the total number of physics students and $\mathrm{PhD}$ faculty members was 2300 and 240 , respectively. Equivalent to the BSc degree are the 4- 5 year degree courses (Licenciatura) in physics, physical engineering, applied physics and geophysics (the latter at only one university). Most universities also offer a four-year Licenciatura in physics teaching. In general, there is a rather pronounced emphasis on teaching theoretical as opposed to experimental physics.

MSc courses were started in 1982 and are now offered at five universities (they have awarded $91 \mathrm{MSc}$ degrees in the last five years). $\mathrm{PhD}$ degrees awarded by Portu-

\section{The Portuguese Physical Society}

The Portuguese Physical Society was established in 1974 following the division of the Portuguese Society of Physics and Chemistry which had been founded in 1965. The Society, with some 1700 members ( $55 \%$ teachers, $25 \%$ research physicists and academic staff, $20 \%$ students) publishes Gazeta de Fisica, an 80-page bulletin distributed four times a year to members, and Portugaliae Physica devoted to scientific communications and reviews. It organizes a well-attended ( 600 participants) biennial national physics conference as well as biennial conference for Iberian physics teachers in collaboration with the Royal Spanish Physical Society. The two societies are also organizing the 1996 EPS-10 General Conference Trends in Physics (Seville; 9-13 Sept.)

guese universities was relatively rare until the beginning of the 1980 s, so a large fraction of today's academic physicists received their degrees abroad, mostly in the UK, France and the US. This feature is in part responsible for the high level of international collaboration in physics research that Portuguese groups have sustained and developed. In recent years, an increasing percentage of the new $\mathrm{PhDs}$ obtained their degree in Portugal ( 66 $\mathrm{PhDs}$ were awarded by six universities in the last five years).

An assessment of the performance of Portuguese universities was only recently started, and physics was one of the first degrees to be selected. The process of evaluation is still underway and a report is not yet available. Only teaching at undergraduate and graduate levels it to be assessed: research activity will not be evaluated, which is surprising but consistent with the fact that the university budget does not specifically contemplate research activity.

\section{Opportunities for Physicists}

Most physicists in Portugal are employed by universities and state laboratories and very few by industry. Unlike many other EU countries, no major industrial company employs a regular and sizable number of physicists. Many students, maybe more than $50 \%$, leaving university with a physics degree become school teachers even though many do not have a Licenciatura in physics teaching.

\section{CIEENCIA and PRAXIS XXI have}

launched a very ambitious programme of $\mathrm{MSc}$ and $\mathrm{PhD}$ grants in science and technology. Physics has greatly benefited from this programme, but employment opportunities for these young MScs and PhDs are rather limited. Recruitment by the universities is at present severely restrained, particularly in the larger physics departments in the older universities. The situation is aggravated by the fact that after fin-

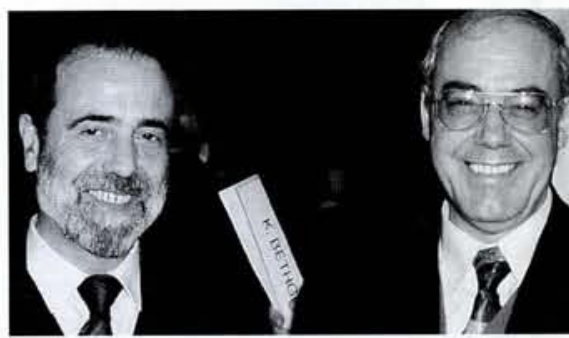

The photograph shows C. Matos Ferreira, on the left, the General Secretary of the Portuguese Physical Society, with J. Bessa Sousa, the Society's President, at the EPS 1996 Council held in Lisbon in March (K. Bethge is in the background).

ishing their $\mathrm{PhD}$, teaching assistants are normally appointed to a tenure track assistant professor's position by the university in accordance with a rather outdated statute of the Ministry of Education. These forced internal appointments are quite unfair to outside $\mathrm{PhDs}$ seeking employment and detrimental to the pursuit of excellence in universities. Furthermore, although a research career within a university is possible, the number of tenure-track research positions is very small and has not increased for many years.

The government-funded polytechnics which account for about $30 \%$ of the number of higher education students may become an important source of employment since less than only $3 \%$ of their teaching staff have $\mathrm{PhD}$ degrees (the figure for the state universities is about $36 \%$ ). Data on physics PhDs appointed by polytechnics is almost non-existent at present.

A distinctive characteristic of physics research in Portugal is the strong international collaboration and networking. A significant number of foreign physicists, mainly from Europe, visit the most active research groups for periods of time ranging from months to two years. Groups have achieved a high level of excellence in practically all areas of physics, and also in astronomy and geophysics. It may be relevant to mention that the Portuguese are in general very hospitable and the country is rather pleasant to live in and to visit.

\section{Acknowledgments}

J.M. Gago, A.M. Eiro and M.J. Marcha are thanked for reading and improving the manuscript and the JNICT for providing most of the statistics on research funding.

\section{References}

[1] Gazeta de Fisica 13 (1990) 3.

[2] Science 271 (1996) 898.

[3] Guide to RळD in Portugal (Secretaria de Estado da Ciencia e Tecnologia, Lisbon, 1995).

[4] A.M. Eiro in Physics Studies for Tomorrow's Europe, Ed: H. Ferdinande (University of Ghent, 1995). 